\title{
Operation of a high-gradient superconducting radio-frequency cavity with a non-evaporable getter pump
}

\author{
G. Ciovati ${ }^{a,}{ }^{,}$, R. Geng ${ }^{a}$, Y. Lushtak $^{b}$, P. Manini ${ }^{b}$, E. Maccallini ${ }^{b}$, M. Stutzman ${ }^{a}$ \\ ${ }^{a}$ ThomasJefferson National Accelerator Facility, Newport News, VA 23606, USA \\ ${ }^{b}$ SAES Getters, S.p.A, Viale Italia, 77, 20020 Lainate MI, Italy
}

\begin{abstract}
The use of non-evaporable getter (NEG) pumps in particle accelerators has increased significantly over the past few years because of their large pumping speed, particularly for hydrogen, compared to the size of the pump. A concern about using such pumps in superconducting radio-frequency (SRF) accelerators is the possibility of shedding particulates which could then migrate into the SRF cavities and produce field emission, therefore degrading the cavity performance. One option to mitigate such issue is to use sintered getter materials which intrinsically offer superior mechanical and particle retention properties.In this article we present the results from cryogenic RF tests of a high-gradient SRF cavity after being evacuated several times with an NEG pump equippedwith sintered getter disks and placed in close proximity to the cavity. The results showed that the cavity performance was not affected by the pump up to the quench gradient of $34 \mathrm{MV} / \mathrm{m}$. As a result of this study, two such NEG pumps have been installed next to a cryomodule in the CEBAF accelerator to maintain ultra-high vacuum in the SRF cryomodule and two adjacent warm girder sections.
\end{abstract}

Keywords:superconducting cavities, vacuum pumps, field emission

\section{Introduction}

Non-evaporable getter (NEG) pumps are a valuable option to achieve and maintain ultra-high vacuum (UHV) in particle accelerators because of their high pumping speedfor all getterable gases like $\mathrm{H}_{2}, \mathrm{~N}_{2}$, $\mathrm{H}_{2} \mathrm{O}, \mathrm{CO} / \mathrm{CO}_{2}$ and $\mathrm{O}_{2}$, compact size and ease of operation [1]. NEG pumps are commonly used in particle accelerator, often in combination with ion pumps. Recent examples are in the Swiss-FEL linear accelerator, in the J-PARC accelerator [2], in undulators at Cornell, BNL, Taiwan Photon Source [3] and Spring-8 [4], in a large monochromator chamber at LCLS, in the CLIC Test Facility [5] and ELENA accelerators at CERN [6] and in the beam transport area of the E-XFEL. They are also used in the CEBAF electron gun at Jefferson Lab [7] and in the electron gun for the ERL prototype at Cornell [8]. NEG pumps

${ }^{*}$ Corresponding author.

E-mail address: gciovati@jlab.org

Phone: 757-269-5945

Fax: 757-269-7658

(C) 2016. This manuscript version is made available under the Elsevier user license http://www.elsevier.com/open-access/userlicense/1.0/ 
equipped with sintered disks are used in several particle sensitive applications such as photocathode transportation [9] and electron microscopes $[10,11]$ as well as in several advanced accelerators facilities [2]. The getter sintering process[12] is a high temperature process carried out under vacuum with the purpose to bound the getter powder grains together, consolidating them in one single body, This intrinsically mitigate the risk that grains of getter powder may be released during the pump operation. Getter disks with good mechanicalstability, high porosity and large surface area, thus able to deliver large pumping speed and capacity, can be obtained by adjusting and optimizing the sintering process. To the authors' knowledge, the CESR accelerator at Cornell [13] is the only accelerator in which a NEG pump using sintered getters is located close to a single-cavity SRF cryomodule. The SRF cavity operation at an accelerating gradient of $\sim 7 \mathrm{MV} / \mathrm{m}$ in CESR was not affected in terms of field emission by the presence of the NEG pumps[14].

Field emission is one of the major mechanisms limiting the performance of SRF cavities in accelerators [15-17]. Particulates generated from beamline components such as gate valves and ion pumps can migrate into the cavities and trigger field emission [18]. Residual gases adsorbed on the surface of SRF cavities can also lead to field emission [19], resulting in lower accelerating gradient and higher cryogenic heat load. It is also important to achieve and maintain ultra-high vacuum not only in the cryomodule but also in the warm section of a superconducting accelerator, therefore gases released for example by electron-stimulated desorption should be efficiently pumped in the warm section to prevent them condensing on the cold cavity surface and potentially triggering field emission.

In 2014, a new type of sintered gettering medium based on Ti-Zr-V-Al alloy (ZAO ${ }^{\circledR}$ ) [20] was developed by SAES Getters S.p.A. and one of the advantages of this new alloy is reduced particulate shedding when activated and during operation compared to the previously availablegetter alloys. The purpose of this study is to evaluate the compatibility of a ZAO-based CapaciTorr ${ }^{\circledR}$ HV200 NEG pump with the operation of an SRF single-cell cavity up to high accelerating gradient, with respect to particulate contamination resulting from the in-situ activation and operation of the pump.

\section{Experimental Setup}

A 1.3 GHz single-cell cavity labelled "G2" of the TESLA end-cell shape [21] was used for this study. The cavity was fabricated from high-purity (residual resistivity ratio $>300$ ) ingot niobium discs, $3.17 \mathrm{~mm}$ thick, from Tokyo Denkai, Japan. The cavity was processed and tested several times for other studies prior to the one presented in this article. The initial surface processing of G2 consisted of "mirror-finish" $180 \mu$ mmechanical polishing, vacuum furnace outgassing at $800^{\circ} \mathrm{C}$ for $3 \mathrm{~h}, 30 \mu$ melectropolishing (EP) and in-situ baking at $120{ }^{\circ} \mathrm{C}$ for $48 \mathrm{~h}$. Later on, this cavity was nitrogen doped $\left(800{ }^{\circ} \mathrm{C}\right.$ for 3 hours, 2 minute nitrogen exposure at $\sim 20$ mTorr, 30 minutes annealing at $800^{\circ} \mathrm{C}$ with nitrogen pumped out of the furnace chamber), and $10 \mu \mathrm{m}$ removal in the equator region by EP. Ultimately, additional surface removal of $35 \mu \mathrm{m}$ was carried out by EPand some of the cavity test results are given in $[22,23]$. In preparation for the first RF test at $2 \mathrm{~K}$ as a part of this study, the cavity was degreased, high-pressure rinsed with ultra-pure water, dried in an ISO 5 clean room, assembled with a top flange with a pick-probe and a bottom flange with both a $1.73 \mathrm{~mm}$ inner diameter $90^{\circ}$ elbow ending with a 2 $3 / 4$ "CFflange and an input antenna. AlMg 3 gaskets were used to seal the cavity flanges. 
The NEG pump used for this study was a CapaciTorr ${ }^{\circledR}$ HV 200 built with a $2 \frac{3 / 4}{}$ " CF flange. A diagram of the vacuum system connecting the NEG pump to the cavity is shown in Fig. 1(a) and a picture of the assembly is shown in Fig. 1(b). The turbo-pump station has a cold-cathode ion gauge (CCG), a residual gas analyzer (RGA) and an inlet line to vent the system to atmosphere with filtered N2. Thepumping speedS of the NEG pump at the pump inlet from the manufacturer along with the effective pumping speed $S_{\text {eff }}$ at the entry of the SRF cavity estimated from the conductance of the vacuum circuit are given in Table 1.

The vacuum components were attached to the cavity in the ISO 5 clean room after standard UHV cleaning consisting of degreasing with a detergent diluted in ultra-pure water and with ultrasonic agitation, followed by multiple rinses with ultra-pure water. After unpacking, only the outer body of the NEG pump was wiped clean with isopropanol before transferring in the clean room. Prior to assembly, a jet of filtered ionized nitrogen at $4.8 \mathrm{~atm}$ is blown into the pump body about $15 \mathrm{~cm}$ above the inlet of a particle counter (Solair 3100, Lighthouse Worldwide Solutions) to remove any loose particulate. A plot of the particulatescount as a function of time is shown in Fig. 2, showing that the counts drop close to zero after a little more than one minute of spraying.

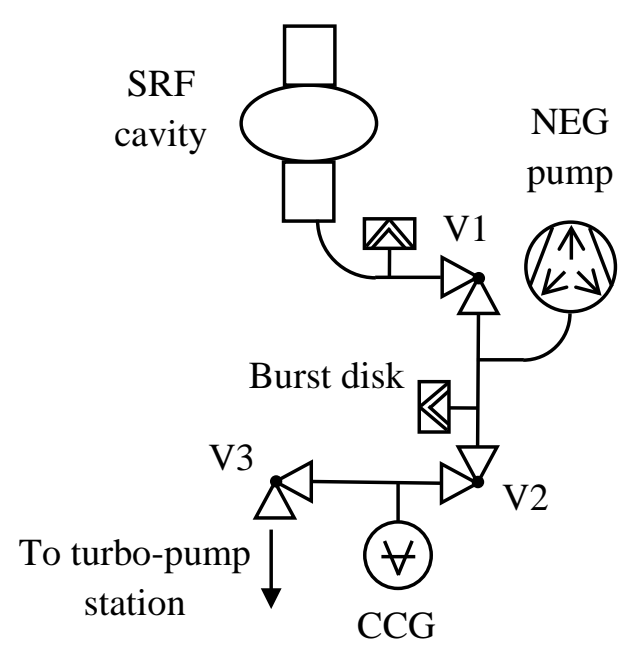

(a)

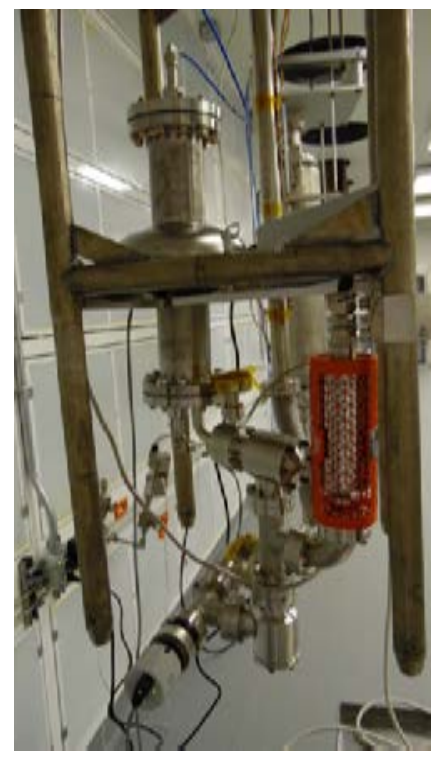

(b)

Fig. 1. Schematic of the vacuum circuit attached to the single cell cavity (a) and picture of the assembly hanging from a test stand (b). 


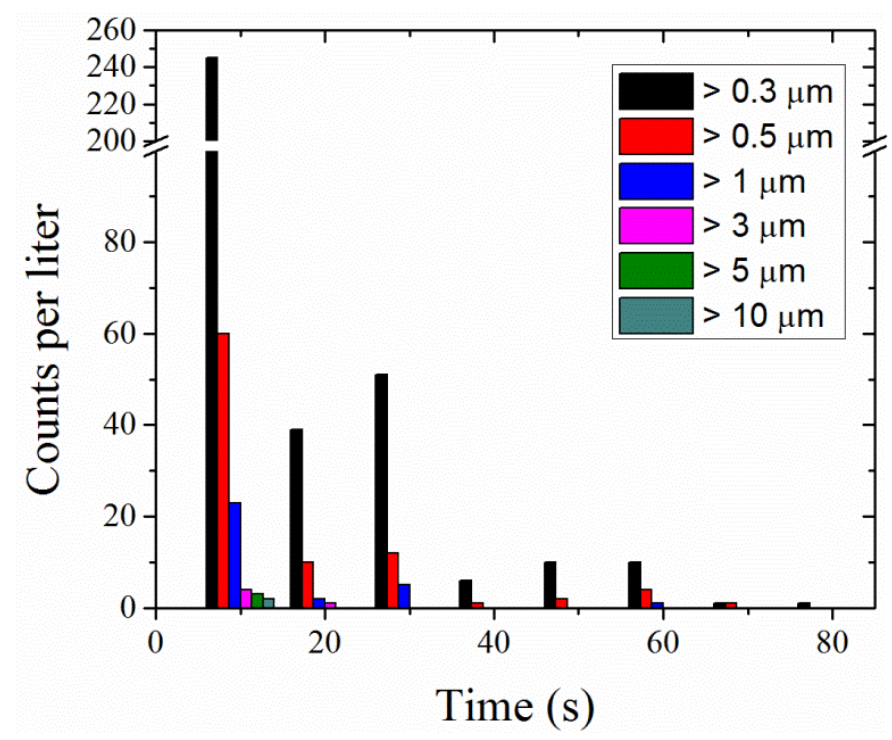

Fig. 2. Cumulative particulate count versus time for particles of different sizes acquired at $10 \mathrm{~s}$ intervals while spraying the getter alloy with filtered ionized nitrogen before assembling in the vacuum system.

Table 1. Pumping speed $\mathrm{S}$ from the manufacturer and estimated from the conductance of the vacuum circuit.

\begin{tabular}{|l|l|l|}
\hline Gas & $\mathrm{S}(\mathrm{l} / \mathrm{s})$ & $\mathrm{S}_{\text {eff }}(\mathrm{I} / \mathrm{s})$ \\
\hline $\mathrm{H}_{2}$ & 105 & 11 \\
\hline $\mathrm{O}_{2}$ & 32 & 3 \\
\hline $\mathrm{CO}_{2}$ & 25 & 2 \\
\hline $\mathrm{N}_{2}$ & 30 & 3 \\
\hline
\end{tabular}

\section{Test results}

In preparation for the first RF test, to be considered as a baseline, the cavity was evacuated to $1 \times 10^{-8}$ mbar using the turbo-pump station before closing valves V1, V2 and V3. In this case, the NEG pump was only part of the vacuum system and was not activated. The cavity with vacuum system was disconnected from the turbo-pump station at valve $\mathrm{V} 2$ and it was hungon a vertical test stand and the RF cables were connected to the input and pick-up feedthroughs. The test stand was then inserted in a vertical cryostat filled with liquid $\mathrm{He}$ at $4.3 \mathrm{~K}$. The temperature was lowered to $2 \mathrm{~K}$ by pumping on the $\mathrm{He}$ bath and maintained to such value as the quality factor $Q_{0}$ was measured as a function of the accelerating gradient $E_{\text {acc }}$ by the standard phase locking technique [24]. The radiation at the cryostat's top plate was measured by gamma probes during the high-power test. The onset of field emission is defined as the $E_{\text {acc }}$ value at which the rate of dose equivalent becomes higher than $0.3 \mu \mathrm{Sv} / \mathrm{h}$. The results from test 1 are shown in Fig. 3. No field emission was detected up to the quench field of $(34 \pm 2) \mathrm{MV} / \mathrm{m}$. 
Bursts of $x$-rays occurred at $\sim 27 \mathrm{MV} / \mathrm{m}$ due to multipacting which was conditioned after $\sim 10 \mathrm{~min}$ of RF processing and resulted in a reduction of $Q_{0}$ by $\sim 14 \%$.

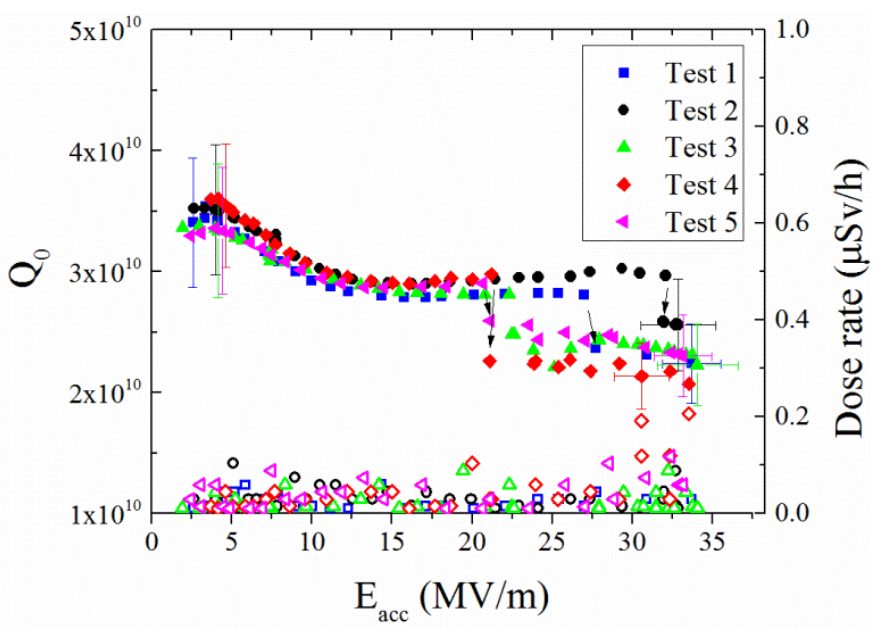

Fig. 3. $Q_{0}$ vs. $E_{\text {acc }}$ (solid symbols) and x-rays dose rate vs. $E_{\text {acc }}$ (empty symbols) measured at $2 \mathrm{~K}$ for the 1.3 $\mathrm{GHz}$ single-cell cavity with the NEG pump. Please refer to the text and Table 2 for evacuation procedures and pump operation before each test. The dose rate threshold corresponding to the onset of field emission is $0.3 \mu \mathrm{Sv} / \mathrm{h}$. The drop of $Q_{0}$ between $20-30 \mathrm{MV} / \mathrm{m}$ during all the tests resulted from the processing of multipacting.

After the test, the vacuum system was disassembled and the cavity and vacuum components were recleaned, re-assembled and evacuated with the turbo-pump station as it was done in preparation for the first test. The RF test results from test 2 , after repeating the cleaning and assembly procedures, are shown in Fig. 3 . The cavity quenched at $(33 \pm 2) \mathrm{MV} / \mathrm{m}$ with no field emission.

After test 2, the cavity assembly was moved back into the clean room and connected to the turbo-pump station. Valves V3 and V2 were opened and the NEG pump was activated by connecting it to a power supply providing $54 \mathrm{~W}$ to heat the getter alloy to $530-570^{\circ} \mathrm{C}$ for $1 \mathrm{~h}$. Afterwards, the power supply was set to "heating mode" which delivers $7.5 \mathrm{~W}$ to maintains the getter at $\sim 200{ }^{\circ} \mathrm{C}$, valve V3 was closed and valve V1 was opened. The cavity was pumped by the NEG pump for 3 days, then V1 and V2 were closed, the assembly was disconnected from the turbo-pump station at valve $\mathrm{V} 2$ and hung on the test stand. The results from test 3 are shown in Fig. 3. The cavity quenched at $(34 \pm 2) \mathrm{MV} / \mathrm{m}$ with no field emission. Burst of $x$-rays were measured during conditioning of multipacting at $\sim 23 \mathrm{MV} / \mathrm{m}$, which resulted in a degradation of the quality factor by $\sim 12 \%$.

After test 3, the cavity assembly was moved back into the clean room and connected to the turbo-pump station. Valves V1, V2 and V3 were opened and a spectrum of the residual gases was measured (Fig. 4). Hydrogen, water, nitrogen/carbon monoxide and carbon dioxide are the major residual gases as typical 
for an unbaked, clean vacuum system. Valve V3 was closed, the power supply in "heating mode" was plugged into the NEG pump opened to the cavity for $\sim 5 \mathrm{~h}$. Afterwards, V1 was closed, the power supply switched off and the space between V1 and V3 was vented to 1 atmosphere and re-evacuated with the turbo-pump station. Afterwards, valves V2 and V3 were closed and the cavity with vacuum assembly were disconnected from the turbo-pump station at valve V2 and hung on a test stand which was inserted in the vertical cryostat. The results from test 4 are shown in Fig. 3. The cavity quenched at (34 \pm 2) $\mathrm{MV} / \mathrm{m}$ with no field emission. Burst of $\mathrm{x}$-rays were measured during conditioning of multipacting at $\sim 21 \mathrm{MV} / \mathrm{m}$, which resulted in a degradation of the quality factor by $\sim 23 \%$.

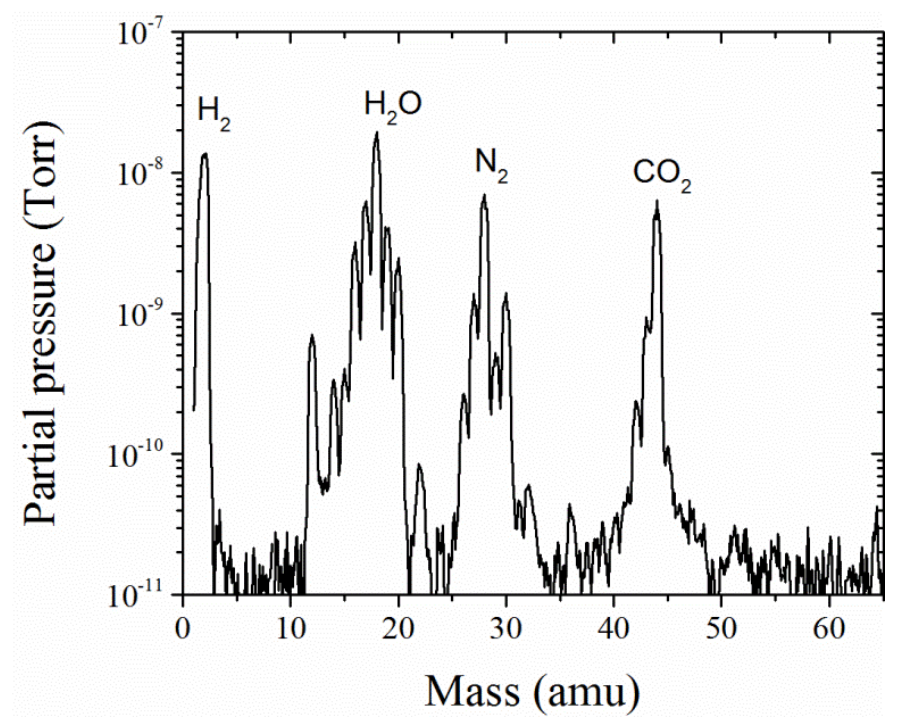

Fig. 4.Partial pressures of the residual gases in the cavity assembly.

After test 4, the cavity assembly was connected back to the turbo-pump station in the clean room, valves V3 and V2 were opened and the NEG pump was re-activated for $2 \mathrm{~h}$ and then switched to "heating mode". Valve V1 was opened, V3 and V2 closed. The cavity was evacuated by the NEG pump for $~ 7$ days and a plot of the pressure versus time measured by the cold-cathode gage is shown in Fig. 5 . The pressure became lower than the gage resolution of $5 \times 10^{-9} \mathrm{mbar}$ after pumping for about 4 days. Valve V1 was closed after $\sim 6$ days of pumping with the NEG pump, the power supply disconnected and the cavity was tested at $2 \mathrm{~K}$ one last time. The results from test 5 , shown in Fig. 3, showed that the cavity quenched at ( $33 \pm 2$ ) MV/m with no field emission. Multipacting occurred at $\sim 22 \mathrm{MV} / \mathrm{m}$ causing a reduction of $Q_{0}$.

After test 5 , the cavity assembly was moved back into the clean room and slowly vented to 1 atm at a rate of $\sim 250 \mathrm{~cm}^{3} / \mathrm{min}$. The NEG pump was carefully removed from the assembly and the inside was purged with filtered ionized nitrogen at $4.8 \mathrm{~atm}$ at about $15 \mathrm{~cm}$ above the inlet of a particle counter. The 
result from the particle counts versus time, shown in Fig. 6, showed that the counts dropped to zero after spraying for less than 1 min.A summary of the conditions before each RF test is shown in Table 2.

Table 2: Summary of evacuation conditions prior to each RF test.

\begin{tabular}{|l|l|l|l|}
\hline Test number & $\begin{array}{l}\text { Cleaned and } \\
\text { assembled } \\
\text { prior }\end{array}$ & Evacuation & NEG activation \\
\hline 1 & Yes & Turbo-pump & No \\
\hline 2 & yes & Turbo-pump & No \\
\hline 3 & No & NEG, 3 days & Yes, $1 \mathrm{~h}$ \\
\hline 4 & No & NEG, 5 h & No \\
\hline 5 & No & NEG, 6 days & Yes, $2 \mathrm{~h}$ \\
\hline
\end{tabular}

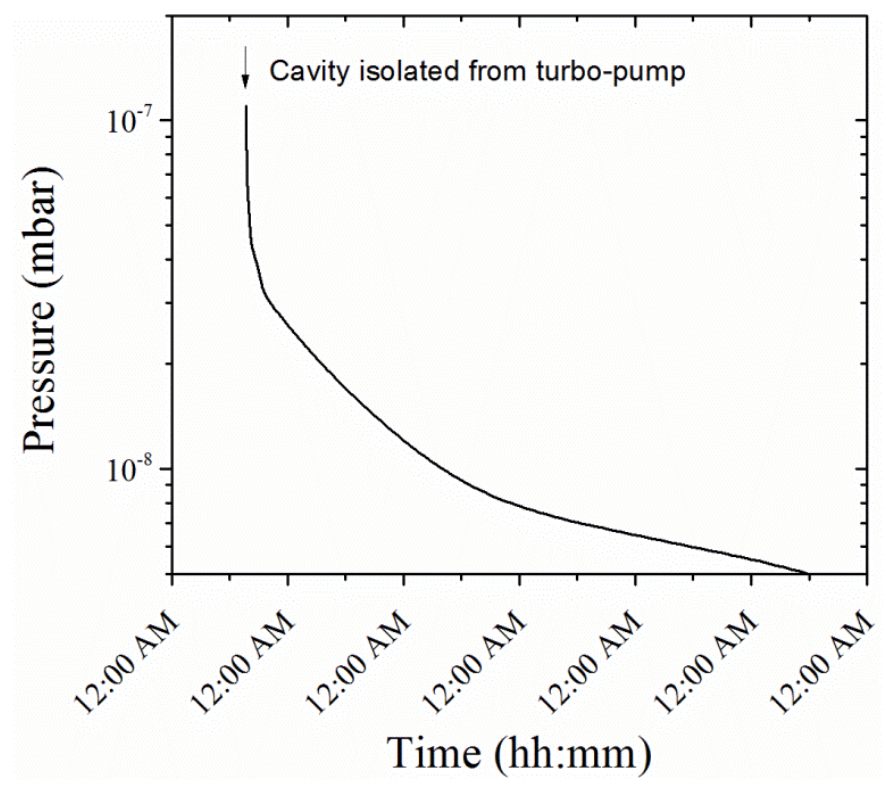

Fig. 5.Cavity pressure versus time while pumping with the NEG pump. 


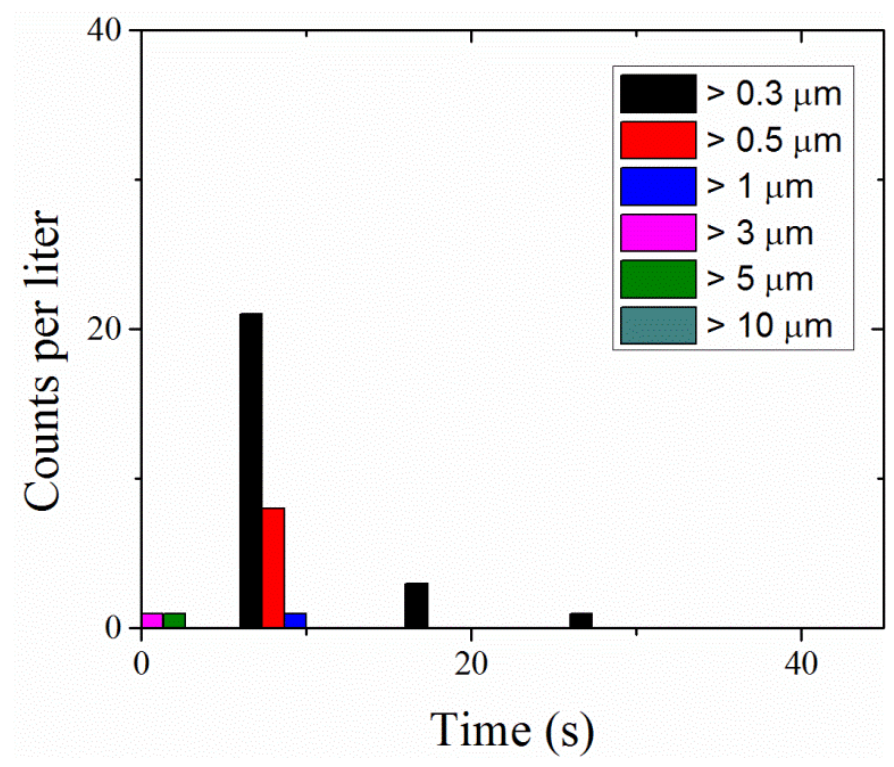

Fig. 6. Cumulative particulate count versus time for particles of different sizes acquired at $10 \mathrm{~s}$ intervals while spraying the getter alloy with filtered ionized nitrogen after disassembly from the vacuum system.

\section{Conclusion}

The results of several high-power RF tests of an SRF cavity in close proximity to a latest-generation NEG pump showed that no performance degradation, in terms of field emission onset, resulted from the activation and operation of the pump up to an accelerating gradient of $34 \mathrm{MV} / \mathrm{m}$, corresponding to a peak surface electric field of $\sim 63 \mathrm{MV} / \mathrm{m}$. The pump itself was robust and reliable as it was thermally cycled five times between $2 \mathrm{~K}$ and $300 \mathrm{~K}$.As a result of this study, two CapaciTorrpump with ZAO ${ }^{\circledR}$ material have been installed next to a cryomodulein the CEBAF accelerator on one cryomodule and one warm section.

\section{Acknowledgements}

The authors would like to acknowledge the Cavity Production Group at Jefferson Lab for cleaning of the cavity, components and most of the assemblies. We would also like to acknowledge A. Fryeberger and $\mathrm{R}$. Rimmer for encouraging us in pursuing this study. This manuscript has been authored by Jefferson Science Associates, LLC under U.S. DOE Contract No. DE-AC05-06OR23177. The U.S. Government retains a non-exclusive, paid-up, irrevocable, world-wide license to publish or reproduce this manuscript for U.S. Government purposes. 


\section{References}

[1] P. Manini, A. Conte, L. Viale, A. Bonucci, F. Siviero, L. Caruso, in: Proceedings of IPAC'11, San Sebastian, Spain, Sept. 4-9, 2011, p. 1536.

[2]H. Ao, H. Asano, J. Tamura, Y. Nemoto, N. Ouchi, F. Naito, K. Takata, in: Proceedings of IPAC'13, Shanghai, China, May 12-17, 2013, p. 3845.

[3] G.Y. Hsiung, H.P. Hsueha, L.H. Wu , C.C. Chang, C.M. Cheng, C.K. Chan , Y.C. Yang, T.Y. Lee, C.S. Huang, C.H. Chang, I.T. Huang, S.W. Chang, S.N. Hsu , J.R. Chen, Vacuum 121 (2015) 245.

[4] T.Bizen, T. Hasegawa, in: Proceedings of IPAC'11, San Sebastián, Spain, Sept. 4-9, 2011, p. 1542.

[5] C. Garion, in: Proceedings of IPAC'11, San Sebastian, Spain, Sept. 4-9, 2011, p. 1569.

[6] R. Kersevan, in: Proceedings of IPAC'15, Richmond, VA, USA, May 3-8, 2015, p. 3119.

[7] M.L. Stutzman, P. Adderley, J. Brittian, J. Clark, J. Grames, J. Hansknecht, G.R. Myneni, M. Poelker, Nucl. Inst. Meth. Phys. Res. A 574 (2007) 213-220.

[8] B. M. Dunham, C. K. Sinclair, I. V. Bazarov, Y. Li, X. Liu, and K. W. Smolenski, in: Proceedings of PAC'07, Albuquerque, NM, USA, June 25-29, 2007, p. 1224.

[9] D. Sertore, P. Michelato, L. Monaco, P. Manini and F. Siviero, J. Vac. Sci. Technol. A 32 (2014) 031602.

[10] K.Kasuya, S. Katagiri, T.Ohshima, S.Kokubo , J. Vac. Sci. Technol. B 28 (2010) L55.

[11] S. Katagiri, T. Ohshima, Microelectronic Engineering 83 (2006) 1058.

[12] E. Giorgi, C. Boffito, M. Bolognesi, Vacuum, 41(1990) 1935.

[13] Y. Li, X. Liu, V. Medjidzade, J. Conway, M. Palmer, in: Proceedings of ECLOUD'10, Ithaca, NY, USA, Oct. 8-12, 2010, p. 83.

[14] Y. Li, Cornell University, private communication, 2016.

[15] C. Reece, B. Madre, L. Doolittle and J. Delayen, in: Proceedings of SRF'99, Santa Fe, NM, USA, Nov. 1-5, 1999, p. 524.

[16] S.-Ho Kim, in: Proceedings of LINAC'08, Victoria, BC, Canada, Sept. 29-Oct. 3, p. 11.

[17] R. L. Geng, in: Proceedings of IPAC'16, Busan, South Korea, May 8-13, 2016, p. 3198.

[18] H. F. Dylla, G. Biallas, L. A. Dillon-Townes, E. Feldl, G. R. Myneni, J. Parkinson, J. Preble, T. Siggins, S.Williams, and M. Wiseman, J. Vac. Sci. Technol. A 17 (1999) 2113.

[19] Q. S. Shu, K. Gendreau, W. Hartung, J. Kirchgessner, D. Moffat, R. Noer, H. Padamsee, D. L. Rubin, J. Sears, IEEE Trans. Magn. 25, No. 2, (1989)1868. 
[20] U.S. Pat. No.US 20140252266 A1 andUS 20160237533 A1.

[21] B. Aune et al., Phys. Rev. ST Accel. Beams 3 (2000)092001.

[22] R.L. Geng, J.K. Hao, K.X. Liu, H.Y. Zhao, C. Adolphsen, Z. Li, in: Proceedings of IPAC'15, Richmond, VA, USA, May 3-8, 2015, p. 3518.

[23] R.L. Geng and S. C Huang, in: Proceedings of IPAC'16, Busan, South Korea, May 8-13, 2016, p. 2344.

[24] H. Padamsee, T. Hays and J. Knoblock, "RF Superconductivity for Accelerators", $1^{\text {st }}$ ed., J. Wiley \& Sons, New York, 1998, Chapter 8. 